\title{
Osmotin-loaded Magnetic Nanoparticles with an Electromagnetic Guidance for the Treatment of Alzheimer's disease
}

Faiz Ul Amin ${ }^{1}$, Ali Kafash Hoshiar ${ }^{2}$, Ton Duc Do ${ }^{2}$, Yeongil Noh ${ }^{2}$, Shahid Ali Shah ${ }^{1}$, Muhammad Sohail Khan ${ }^{1}$, Jungwon Yoon ${ }^{2}$, Myeong Ok Kim ${ }^{1 *}$

${ }^{1}$ Division of Life Science (BK 21), College of Natural Sciences, Gyeongsang National University (GNU), Jinju, 660-701, Republic of Korea

${ }^{2}$ School of Mechanical \& Aerospace Engineering \&ReCAPT, GNU, Jinju, 660-701, Republic of Korea

*Corresponding author

*Myeong Ok Kim, Prof. Ph.D.

Head of Neuroscience Pioneer Research Center,

Head of Brain-Metabolic Neurodegenerative Disease Center,

Department of Biology and Applied of Life Science, College of Natural Sciences,

Gyeongsang National University, Jinju, 660-701, South Korea

Tel.: +82-55-772-1345 Fax: +82-55-772-1349

E-mail: $\underline{\text { mokim@gnu.ac.kr }}$

(Jungwon Yoon contributed equally to this work as corresponding authors.) 


\begin{abstract}
Alzheimer's disease (AD) is the most prevalent age-related neurodegenerative disease, pathologically characterized by the accumulation of amyloid beta $(\mathrm{A} \beta)$ aggregation in the brain. Here, we describe for the first time the development of a new, pioneering nanotechnology-based drug delivery approach for potential therapies of neurodegenerative diseases, particularly AD. We demonstrated the delivery of fluorescent carboxyl magnetic Nile Red particles (FMNPs) to the brains of normal mice using a functionalized magnetic field (FMF) composed of positive- and negative-pulsed magnetic fields generated by electromagnetic coils. The FMNPs successfully reached the brain in a few minutes and showed evidence of the blood-brain barrier (BBB) crossing. Moreover, the best FMF condition was found for inducing the FMNPs to reach the cortex and hippocampus regions. Under the same FMF conditions, dextran-coated $\mathrm{Fe}_{3} \mathrm{O}_{4}$ magnetic nanoparticles (MNPs) loaded with osmotin (OMNP) were transported to the brains of $A \beta_{1-42^{-}}$

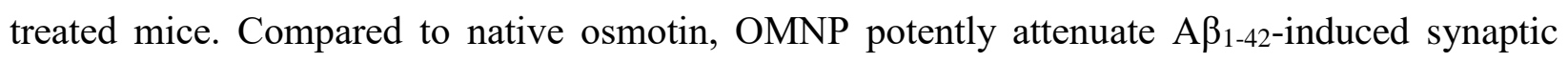
deficits, $A \beta$ accumulation, BACE-1 expression and tau hyperphosphorylation. This magnetic drug delivery approach can be extended to preclinical and clinical use and may advance chance of success in the treatment of neurological disorders like AD in the future.
\end{abstract}

Keywords: Alzheimer's disease (AD), fluorescent carboxyl magnetic Nile Red particles (FMNPs), dextran-coated $\mathrm{Fe}_{3} \mathrm{O}_{4}$ magnetic nanoparticles (MNPs), osmotin, functionalized magnetic field (FMF). 


\section{Introduction}

Alzheimer's disease (AD), a progressive neurodegenerative disorder, is clinically characterized by the dysfunction of memory and cognition. The neuropathological hallmarks of $\mathrm{AD}$ include senile plaques, neurofibrillary tangles, synaptic disorder and neuronal loss. ${ }^{1}$ Several hypotheses have been put forward regarding $\mathrm{AD}$ pathology, although the $\mathrm{A} \beta$ cascade hypothesis is the most widely accepted. ${ }^{2,3}$ According to this hypothesis, $\mathrm{A} \beta$ peptides are prominently generated from the catalytic cleavage of the transmembrane glycoprotein amyloid precursor protein (APP) by $\beta$-secretase at the APP-N terminal and by $\gamma$-secretase at the APP-C terminus. ${ }^{4} \mathrm{~A} \beta_{1-42}$ is neurotoxic both in vitro and in vivo, ${ }^{5,6}$ the primary biochemical cascade associated with memory impairment in $\mathrm{AD} .^{7}$

Osmotin is a 24-kDa multifunctional plant protein from tobacco (Nicotiana tabacum) and a member of the pathogenesis related-5 (PR-5) family of proteins that provides osmotolerance to plants and exhibits antifungal activity. ${ }^{8,9}$ Our group ${ }^{10,11}$ recently demonstrated the neuroprotective effect of osmotin against glutamate- and ethanol-induced apoptosis and neurodegeneration in postnatal rat brains. The neuroprotective effect of osmotin against Alzheimer's disease has been reported by our group in mice. ${ }^{12,13}$

Currently, there is no certain cure for neurological diseases such as $\mathrm{AD}$, and treatment options are extremely limited. ${ }^{14} \mathrm{Fe}_{3} \mathrm{O}_{4}$ MNPs, which are superparamagnetic, non-toxic and biocompatible, have been intensively investigated. ${ }^{15}$ Superparamagnetic iron oxide agents have been modified with dextran and/or other types of polymer coatings to achieve excellent dispersion. ${ }^{16-19}$ Dextran coating enhances the blood circulation time and stabilizes the colloidal solution. ${ }^{20,21}$ Magnetically guided delivery strategies have the potential to enhance the therapeutic profile of a broad range of pharmaceuticals by increasing their distribution to the site of action. ${ }^{22}$ 
MNPs have also attracted attention due to their relatively low toxicity profile. Their superparamagnetic property ensures particle stability during storage and use, and their responsiveness to applied magnetic fields can be exploited for magnetically guided particle imaging. ${ }^{23}$

Magnetic drug delivery refers to adding drugs to magnetizable particles and then applying magnetic fields to concentrate them at disease locations, such as solid tumors, regions of infection, or blood clots. ${ }^{24,25}$ The idea of using permanent magnets for drug delivery has been investigated for the past 30 years. ${ }^{26,27}$ This approach, however, fails to deliver micro-nano agents to deep tissues or provide quick control responses. Using a constant magnetic force or permanent magnets may cause the particles to aggregate or stick to vessel walls, which can lead to blockages. To address this concern, we previously suggested the use of a functionalized magnetic field (FMF), or a field function (FF), to replace the constant magnetic force using an electromagnetic actuator with a high gradient magnetic field. ${ }^{28,29}$ By intentionally changing the direction of the magnetic field, sticking and aggregation were prevented. We also observed that, relative to a constant magnetic field, the rate of magnetic nanoparticle (MNP) uptake and transport across the normal intact BBB was enhanced by a positive/negative pulsed magnetic field through our in vivo experiments with mice. $^{30}$

The primary challenges in the diagnosis (and treatment) of $\mathrm{AD}$ are to overcome the restrictive mechanism of the blood-brain barrier $(\mathrm{BBB})$ and deliver adequate drugs to hippocampus regions located in deeper sites of the brain. Several studies have showed that the hippocampus plays a critical role in learning and memory. ${ }^{31}$ An FMF-guided drug-MNP conjugate for the treatment of AD can reach the CNS and the hippocampus regions within a few minutes, inducing minimal systemic effects. Moreover, the maximum amount of osmotin can reach the 
brain because it is not exposed to body fluids for an extended time. Therefore, FMF-guided OMNP may be more effective and potent in treating Alzheimer's disease. It should be noted that the proposed FMF aims to activate the BBB crossing of the MNPs and spread them over to the broad brain regions for treatments of Alzheimer's disease rather than to target the MNPs to a specific $t$ region of brain like a cancer therapy.

The purpose of this study was to study the delivery effects of osmotin-loaded magnetic nanoparticles to the brains of $\mathrm{A} \beta_{1-42}$-treated mice using an electromagnetic function to guide MNPs into brain sites, which significantly can recover brain damage due to Alzheimer's disease. In our experimental setup, we assessed the differential effects of the electromagnetic guidance on the transport of particles across the intact BBB (Fig. 1). In our experiment, we used an in vivo electromagnetic guidance scheme with the significantly improved process time (9 times shorter) compared to KA. Min et al. 2013. ${ }^{32}$ Also, we demonstrated for the first time that, compared to osmotin, the electromagnetic actuator-guided OMNP reduces $\mathrm{A} \beta$ accumulation, BACE-1 expression, synaptotoxicity, memory impairment and tau hyperphosphorylation in a $A \beta_{1-42-}$ injected mouse model. 

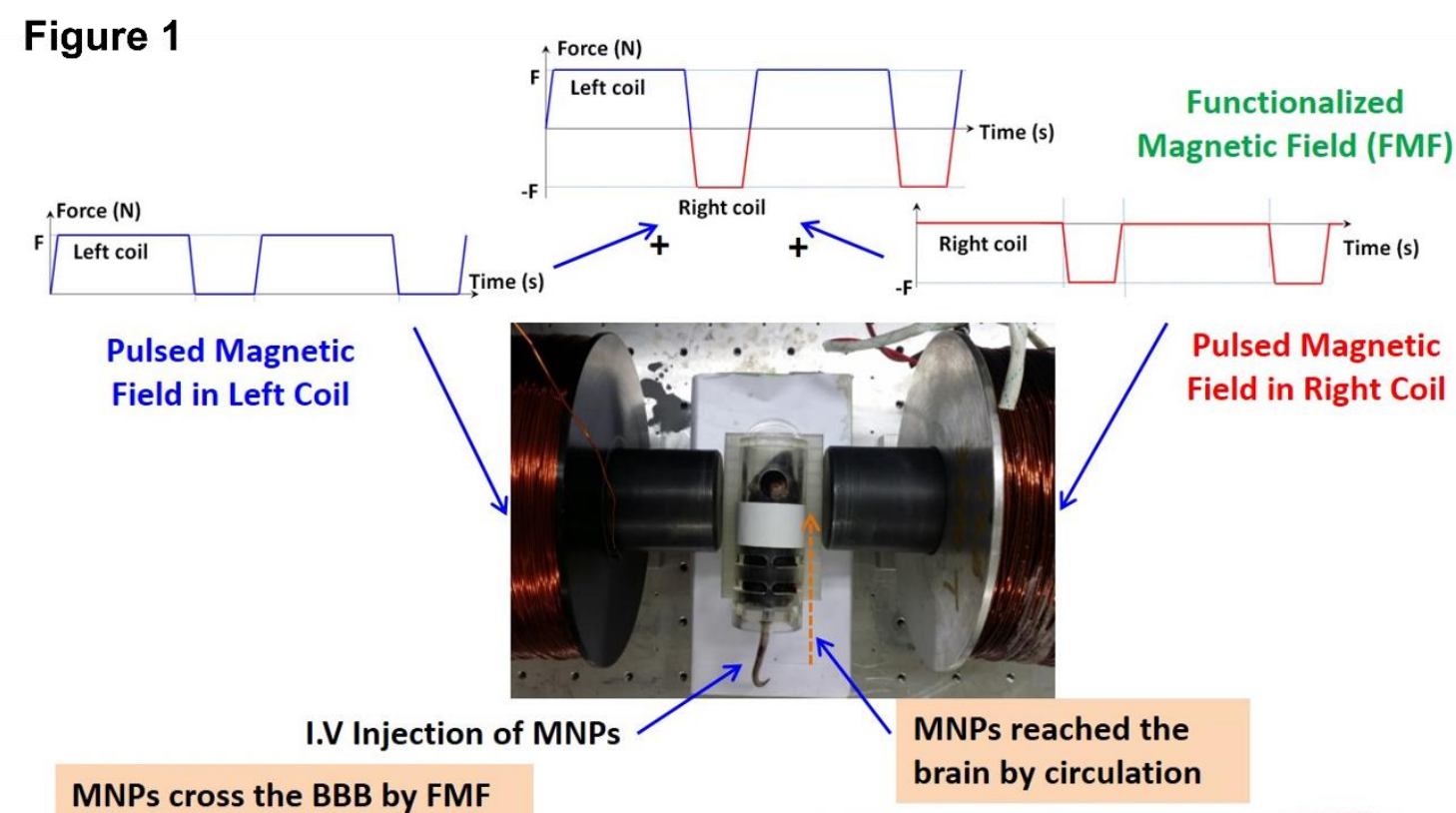

MNPs cross the BBB by FMF

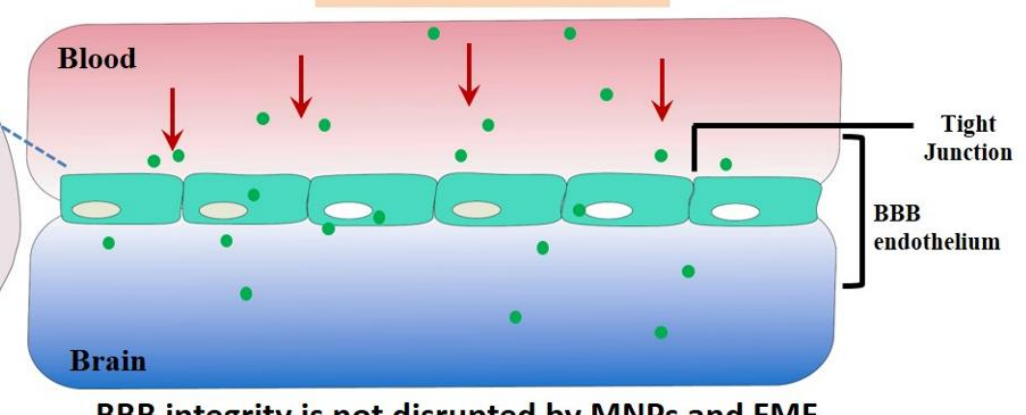

BBB integrity is not disrupted by MNPs and FMF

\section{Results}

\section{Characterization of FMNPs and OMNP}

The FMNPs nanoparticles were $0.20-0.39 \mu \mathrm{m}$ in diameter. Morphological examination via transmission electron microscopy (TEM) revealed the formation of smooth spherically shaped nanoparticles with an average diameter of $350 \mathrm{~nm}$ (Fig. 2A-B). Morphological examination of the osmotin loaded dextran-coated Fe3O4 magnetic nanoparticles (OMNPs) via transmission electron microscopy (TEM) showed smooth spherically shaped nanoparticles with an average diameter of $90 \mathrm{~nm}$ (Fig. 2C-D). 


\section{In vitro cytotoxicity (MTT assay)}

The three nanoparticle cytotoxicity profiles were studied in normal HT-22 cells and human neuroblastoma SH-SY5Y cells using an MTT assay. Various concentrations of each test sample, FMNPs, MNPs, OMNP and free osmotin, were used for the studies. Four concentrations of each test sample were used, ranging from 50 to $200 \mu \mathrm{g} / \mathrm{mL}$. From the results obtained, it was concluded that all of the tested samples did not possess any significant cytotoxic effects, showing $85-90 \%$ viability at all the studied concentrations on HT-22 cells (Fig. 2E \& 2G) and SH-SY5Y cells (Fig. $2 \mathrm{~F} \& 2 \mathrm{H})$. Reduced cytotoxicity of the oxide nanoparticles is associated with increased particle solubility and modifications to the surface chemistry. ${ }^{33}$

Fig. 2
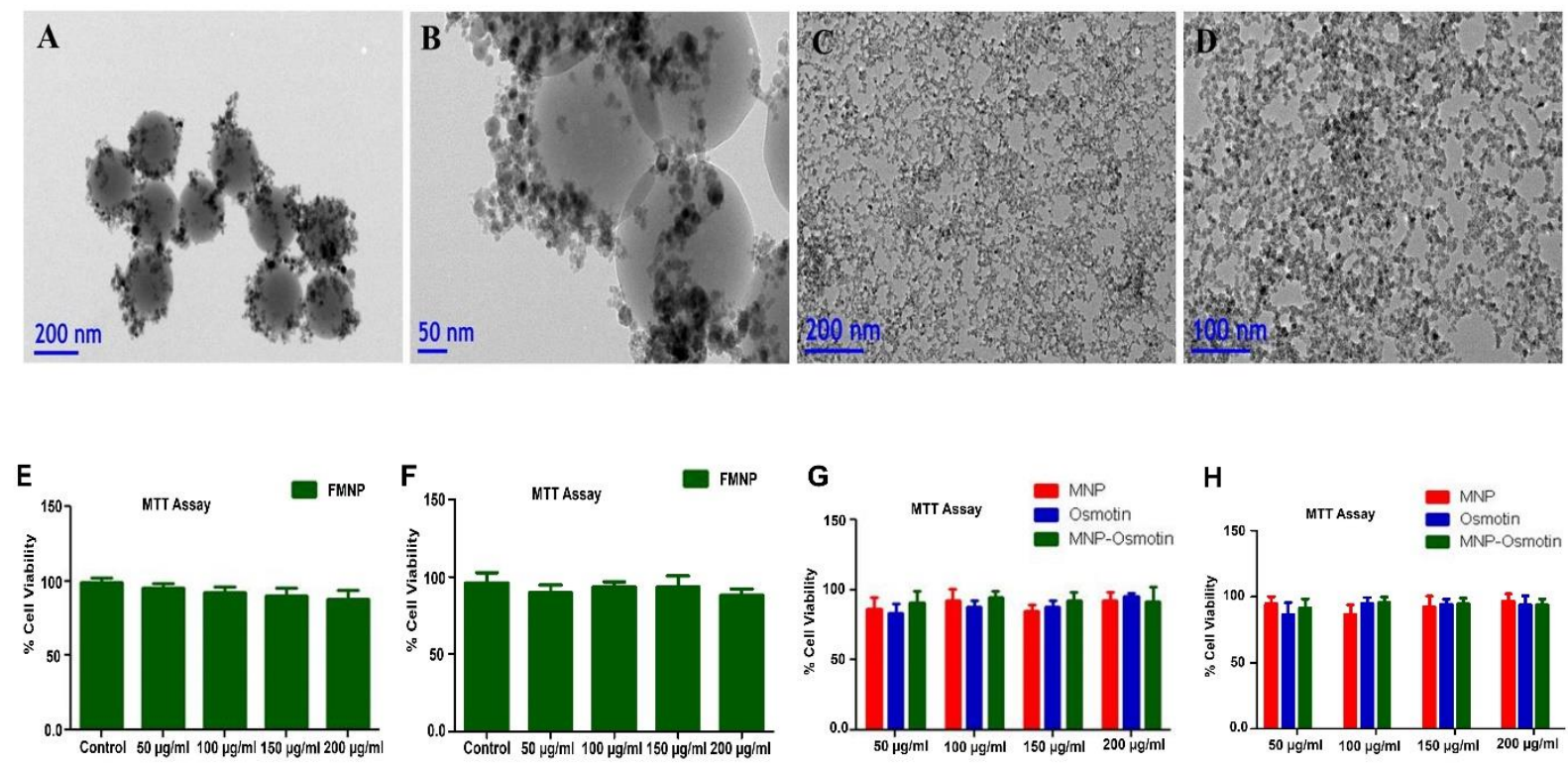


\section{Electromagnetic targeted drug delivery actuator and FMF generation}

The figure 3 shows a picture and the geometric specifications of the proposed electromagnetic actuator. The complete explanation of each part of fig. 3 are provided in experimental section.

\section{Figure 3}

A

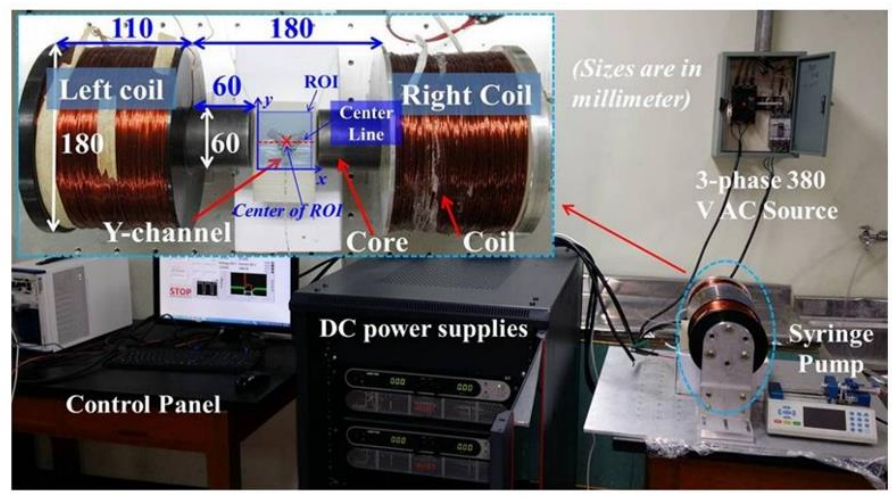

C

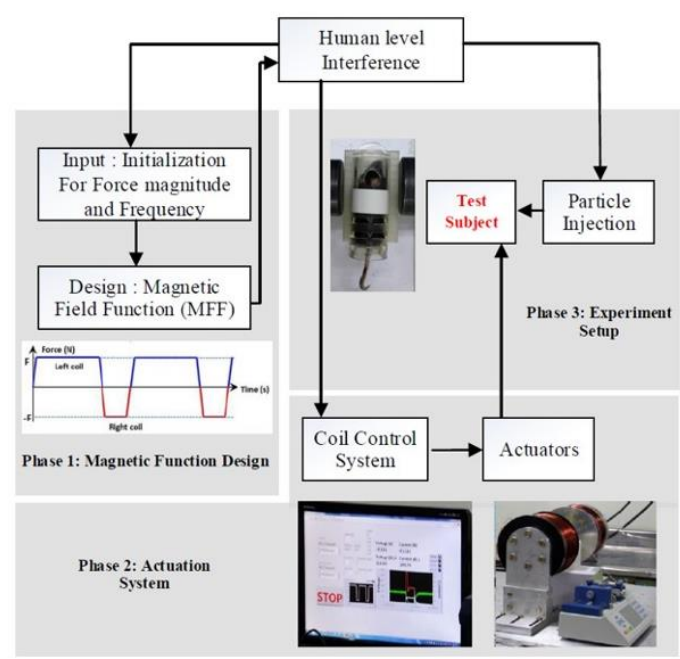

B
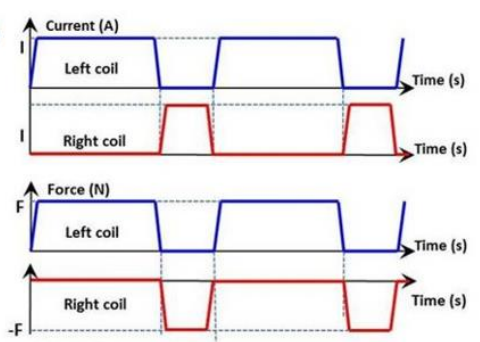

$\uparrow$ Force (N)

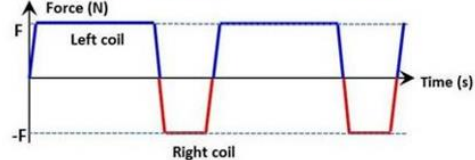

D

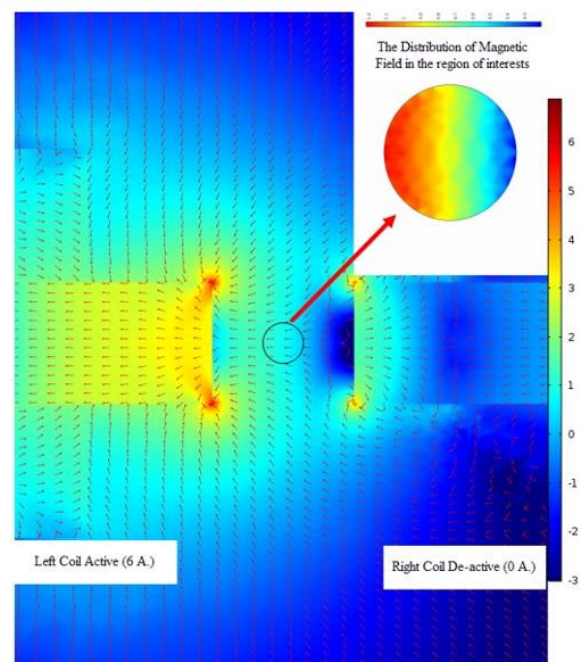

Transport Results of FMNPs across the intact BBB in normal mice promoted by FMFs 
The FMNPs were injected into the mice via the tail vein and then exposed to various magnetic field conditions for different time intervals. The FMNP uptake was verified in the brain by confocal microscopy (Fig. 4 and 5).

To assess the rate and kinetics of MNP accumulation in the brain, we first performed confocal imaging of the brains of mice that were subjected to an intravenous injection of fluorescent MNPs $(0.4 \mathrm{~mL})$ in the absence of FMF. We did not observe the accumulation of MNPs in the brains in the absence of FMF (Fig. 4g). The uptake of FMNPs into the brain was observed when the animals were exposed to FMF. Fig. 4a-f show the confocal micrographs of the brains of the mice that received an intravenous injection of fluorescent MNPs $(0.4 \mathrm{~mL})$ and were then exposed to various FMF conditions for two different time periods. The uptake and transport of the FMNPs were significantly higher $(\mathrm{p}<0.0001)$ at all of the observed experimental FMF conditions (Fig. 4a-f) compared to the control group (Fig. 4g). Figures $4 \mathrm{a}$ and $4 \mathrm{~b}$ show the results of the application of the FMF using an input current of $3 \mathrm{~A}$ and a frequency of $0.5 \mathrm{~Hz}$ for 5- and 10-minute exposure times, respectively. In both conditions, there was uptake and transport of the FMNPs to the brain cortex. To select the most suitable experimental conditions for the uptake and transport of FMNPs to the brain, the current was increased from $3 \mathrm{~A}(2.8 \mathrm{~T} / \mathrm{m})$ to $6 \mathrm{~A}(2.8 \mathrm{~T} / \mathrm{m})$ while using the same frequency. The rate of particle transport across the BBB was increased significantly (Fig. 4c-d). For further confirmation, in the next experimental setup, we kept the current the same and increased the frequency from $0.5 \mathrm{~Hz}$ to $1.0 \mathrm{~Hz}$ (Fig. 4e-f). Compared to the conditions of $6 \mathrm{~A}$ and $0.5 \mathrm{~Hz}$, the transport of MNPs to the brain decreased (Fig. 4c-d), which is discussed in the discussion section.

Overall, our confocal microscopy results showed that, under all of the observed FMF conditions, the FMNPs successfully reached the brain cortex (Fig. 4a-f), indicating that the positive and 
negative pulsing of the magnet promoted both the uptake and transport of FMNPs across the BBB. It should be noted that the uptake and transport across the BBB was significantly increased $(\mathrm{p}<0.01)$ using a current of $6 \mathrm{~A}$ and a frequency of $0.5 \mathrm{~Hz}$ (Fig. 4c-d).

\section{Figure 4}

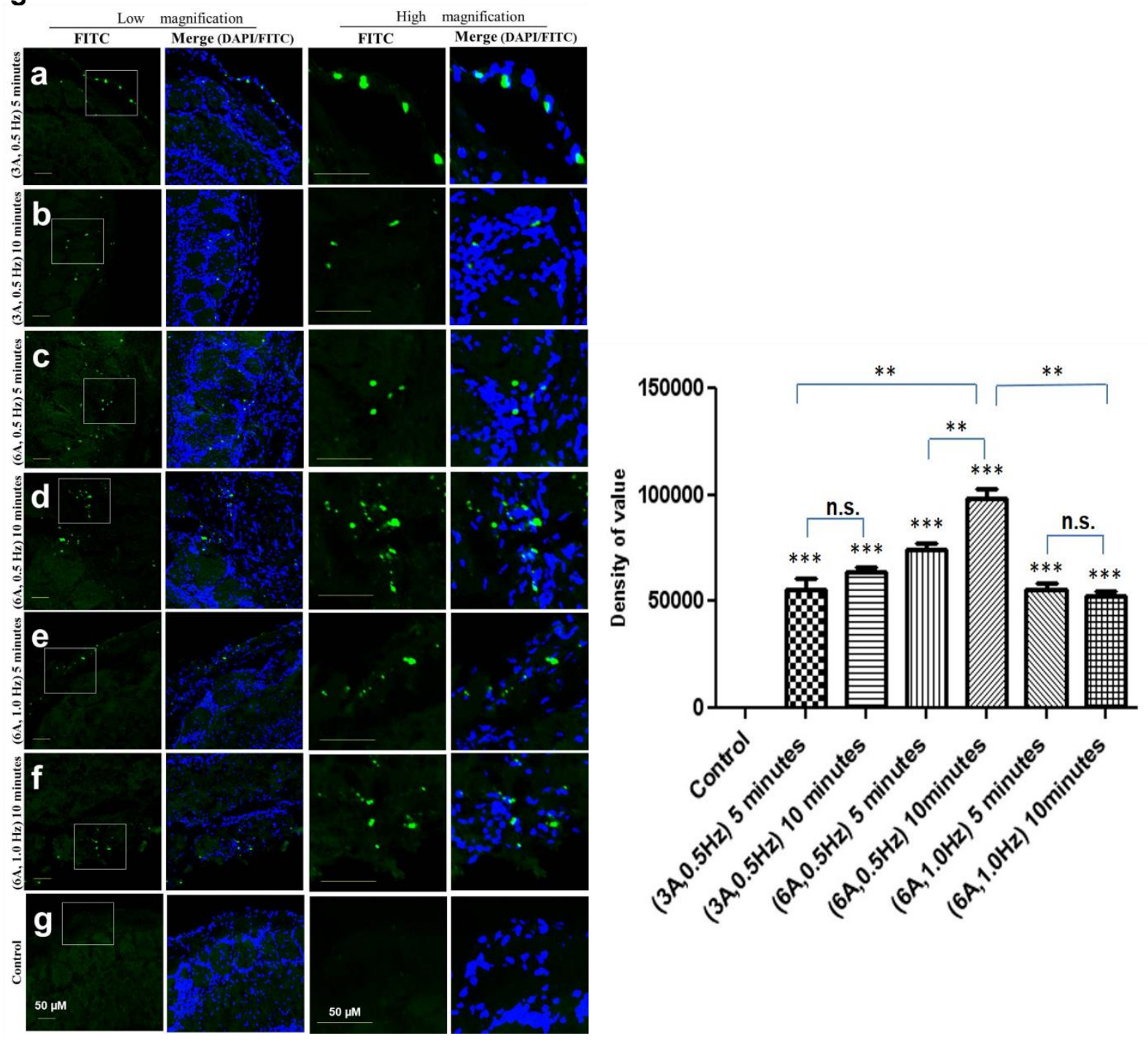

Uptake and transport across the BBB is significantly increased under the $6 \mathrm{~A}, 0.5 \mathrm{~Hz}$ FMF conditions and FMNPs reached the hippocampus of the mice brains 
After confirming that FMNPs crossed the BBB and reached the cortex under all six conditions of FMF (Fig. 4a-f), we next evaluated the hippocampus and observed that the FMNPs reached the hippocampus under the conditions of 6 A, $0.5 \mathrm{~Hz}$ FMF (Fig. 5c-d). However, at all other FMF conditions, we did not observe the presence of FMNPs in the hippocampus (Fig. 5a, b, e, f). Fig. 5 B shows FMNPs present in the CA1, CA3 and DG regions of the hippocampus under the FMF conditions of 6 -A current, $0.5-\mathrm{Hz}$ frequency and a 10-minute exposure time. Thus, we suggest that these FMF conditions are suitable for drug delivery to the hippocampus of AD mice.

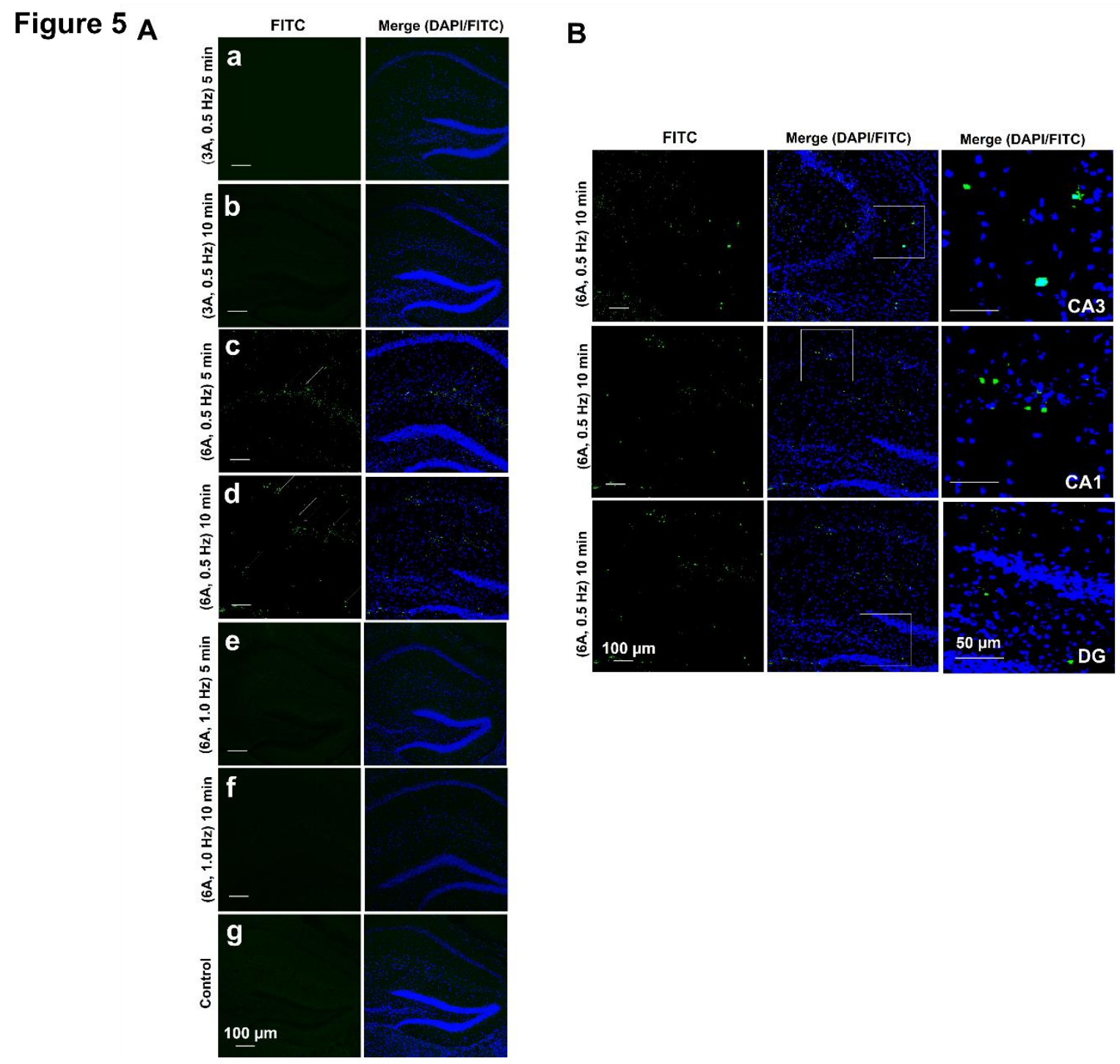




\section{FMNP administration and exposure to FMFs induced no toxicity in vivo in normal mice}

The activation of oxidative stress leading to apoptosis and genotoxicity are the key paradigm(s) of

nanotoxicity. ${ }^{34-38}$ Although MNP deposits were detectable in the prostates of prostate cancer patients after a year of magnetic hyperthermia therapy, no signs of systemic toxicity were found ${ }^{39}$. Following intravenous administration of FMNPs and exposure to the FMFs, the toxicity was studied in tissue lysates of the brain. We did not observe the activation and release of caspase- 3 or PARP-1 in the brain after FMNP injection and exposure to FMFs (Fig. 6A). The western blot results suggest that FMNP administration and the application of FMFs in vivo produced no extended immunotoxicity or cell death in the brain.

The potential toxicity of FMNPs and FMFs was further assessed in brain sections. Nissl/cresyl violet staining was performed to determine the extent of neuronal viability. Histology of the cortex showed that, at all tested conditions, there was no neural cell death after FMNP injection and application of the FMFs (Fig. 6B). These results showed that FMNP administration and the application of FMFs produced no toxicity and neurodegeneration in the brains of mice. 
Figure 6

(A)
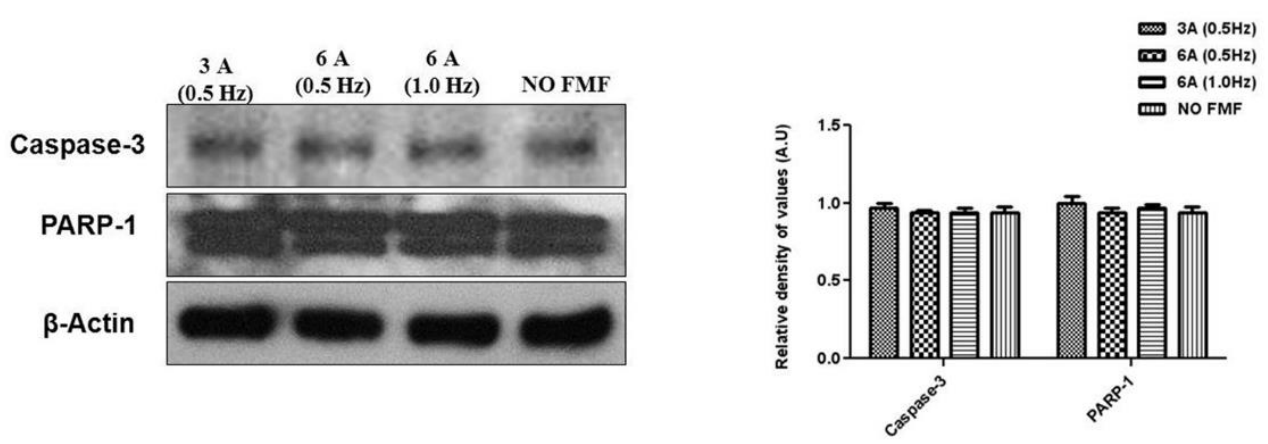

(B)
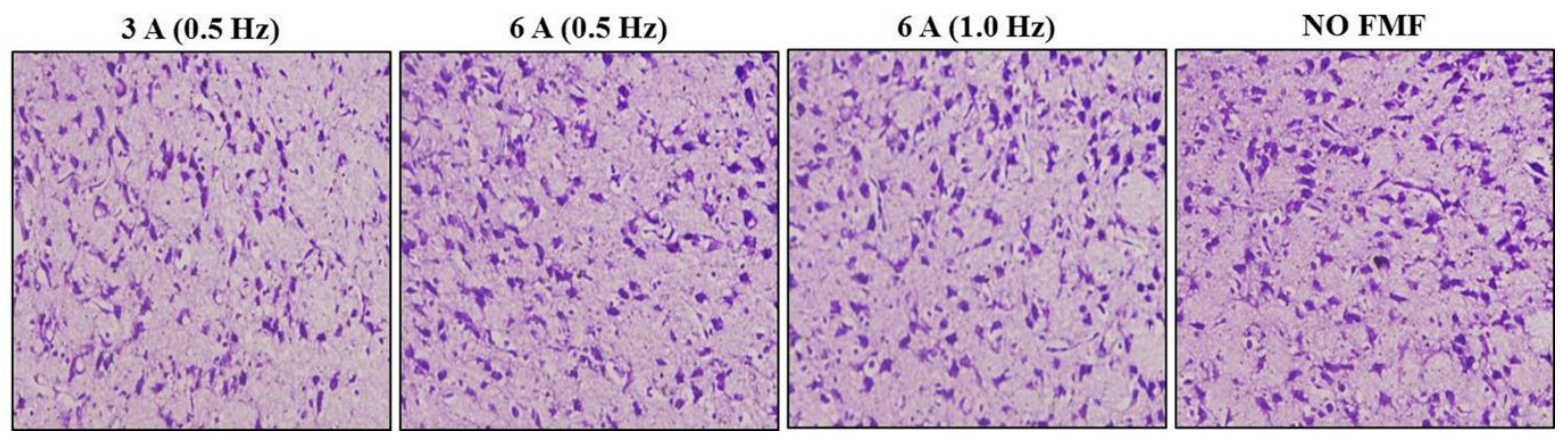

The BBB was not disrupted by the FMNP administration and the application of FMFs in normal mice

For assessing the in vivo nanotoxicity, cell viability measurements should be supplemented with an evaluation of organ-specific toxicity, such as breakdown of the blood-brain barrier. ${ }^{40,41}$ The Evans blue method for macroscopic evaluation of vascular protein leakage across the BBB has been widely used. Its extravasation into central and peripheral organs following a more prolonged time period was correlated with vascular leakage of serum albumin, and its leakage into the brain parenchyma indicated blood-brain barrier (BBB) disruption. ${ }^{42-47}$ The results showed that FMNP administration and the application of the FMFs did not alter the BBB integrity because there was no leakage of Evans blue into the brains of the observed mice. Moreover, after the fluorescence measurements, the values of the control group were the same as the values of the experimental 
groups (data not shown). Therefore, the critical conclusion of these studies is that FMNP uptake into the brain does not cause a major disruption of the endothelial barrier or alteration in BBB integrity.

The apparent intracellular mass of the FMNPs internalized in the brain tissues was also markedly higher under all of the tested FMF conditions. Therefore, an FMF can be used to enhance the transport of FMNPs across the BBB. These results suggest that an FMF is more efficient in promoting FMNP transport because it reduces the aggregation phenomenon of FMNPs and, as a result, the FMNPs can easily penetrate the BBB. More importantly, our results clearly show the importance of exploring the effects of variations in the magnetic field for in vivo magnetic particle delivery applications. The FMF applied for 10 minutes after i.v. injection of FMNPs with a 6ampere current and a $0.5-\mathrm{Hz}$ frequency induced enhanced uptake and crossing of the intact BBB, and the FMNPs subsequently reached to the mouse hippocampus.

Therefore, we used the best condition of FMF for the osmotin delivery to the hippocampus of $A \beta_{1 \text { - }}$ 42-induced $\mathrm{AD}$ mice for the treatment of $\mathrm{AD}$. We injected $\mathrm{OMNP}$ into the $\mathrm{A} \beta_{1-42 \text {-induced } \mathrm{AD} \text { mice }}$ via the tail vein and then exposed the mice to an FMF using a 6-A current and a $0.5-\mathrm{Hz}$ frequency for 10 minutes.

\section{The OMNP treatment ameliorated Aß1-42-induced memory impairment}

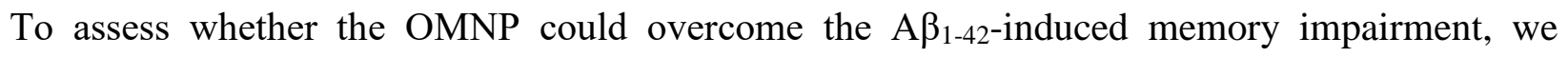
subjected the mice to a Morris water maze (MWM) and a Y-maze test. Using the MWM and observing the learning ability of the mice through the training of a hidden platform, we observed that the $A \beta_{1-42}$-treated mice exhibited higher latencies in seconds to reach the hidden platform and that treatment with osmotin alone or with the OMNP $(15 \mu \mathrm{g} / \mathrm{g}$, body weight, i.v. $)$ reduced the less 
latency times ( $\mathrm{p}<0.05$ and $\mathrm{p}<0.01$, respectively) (Fig. 7A). After the training session, we removed the hidden platform and allowed the mice to swim freely. We observed that the $A \beta_{1-42}$-treated mice exhibited a decreased number of platform crossings indicating $A \beta_{1-42}$-induced memory impairment. Treatment with the OMNP reversed this $A \beta_{1-42}$-induced memory impairment and significantly increasing $(\mathrm{P}<0.01)$ the platform crossing number (Fig. 7B).

Following the MWM analysis, we evaluated the spontaneous alteration behavior percentage (\%) of the mice and found the average total number of arm entries and successive triplets using a Ymaze test. The spontaneous alteration behavior \%, indicating spatial working memory, is a form of short-term memory. After a single injection of $A \beta_{1-42}$, the $\%$ of the spontaneous alteration behavior was reduced in the $A \beta_{1-42}$-treated mice compared to the control mice, suggesting $A \beta_{1-42-}$ induced memory dysfunction. Treatment with the OMNP significantly increased the spontaneous alteration behavior $\%$ in the $A \beta_{1-42}$-treated mice compared to the untreated $A \beta_{1-42}$ mice (Fig. $7 \mathrm{C}$ ), indicating that the OMNP more potently $(\mathrm{P}<0.01)$ ameliorated $\mathrm{A} \beta_{1-42 \text {-induced memory }}$

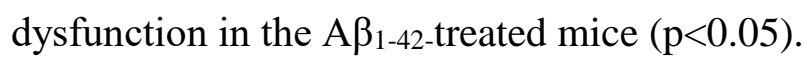


Figure 7
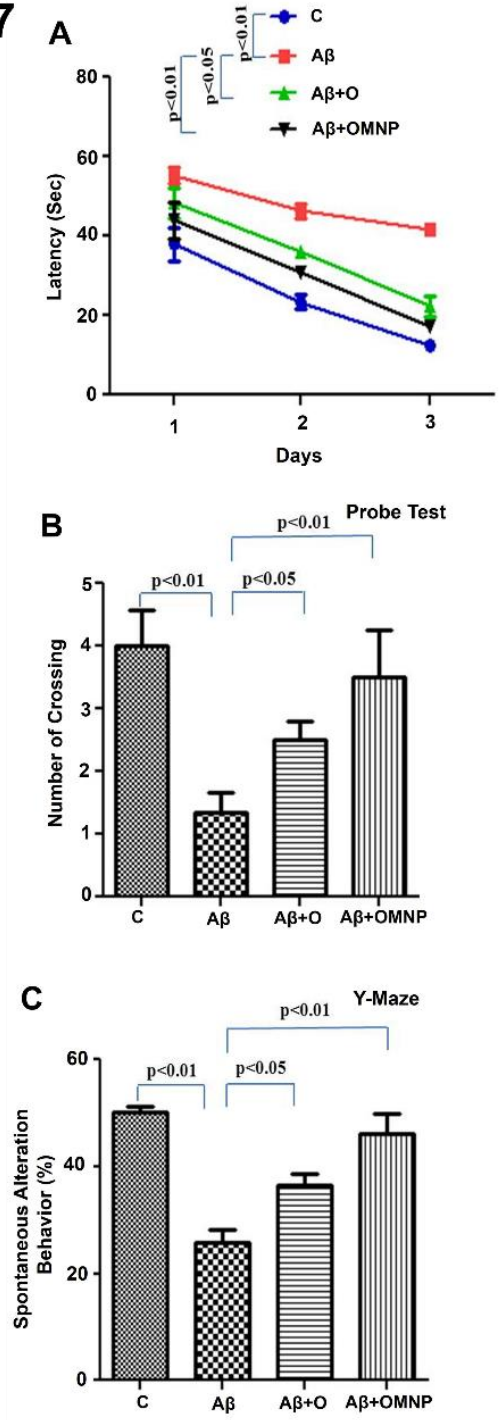
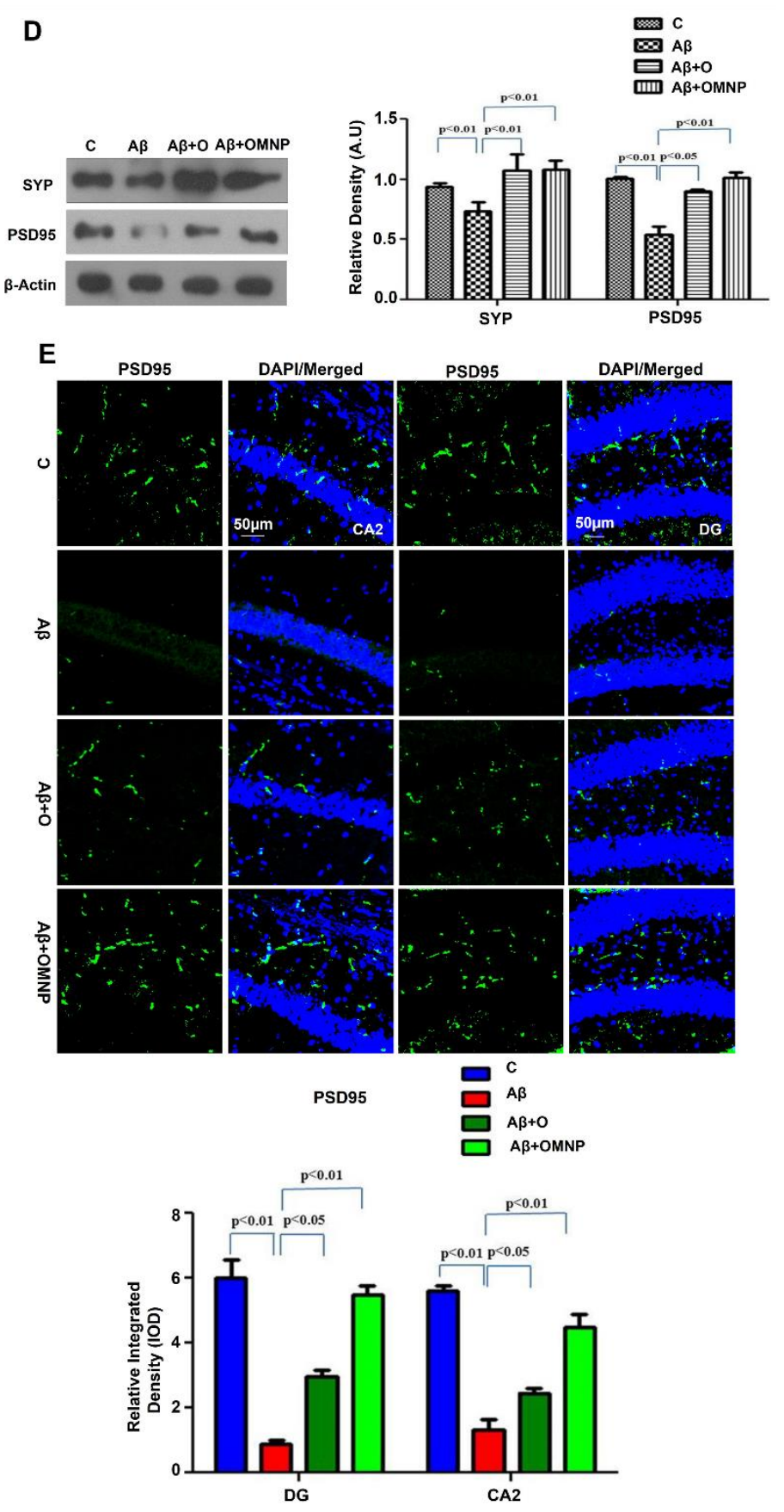

\section{The OMNP treatment alleviated Aß1-42-induced synaptotoxicity}

To assess synaptic integrity after $A \beta_{1-42}$ treatment, we quantified the expression of presynaptic vesicle membrane proteins (synaptophysin) and postsynaptic markers post-synaptic density protein 95 (PSD95). A western blot analysis revealed a significant reduction in synaptophysin 
levels in $A \beta_{1-42}$-treated mice after 40 days post- $A \beta_{1-42}$ injection compared to the control mice, indicating the induction of synaptic dysfunction (Fig. 7D). The OMNP treatment significantly increased $(p<0.01)$ synaptophysin expression after post- $A \beta_{1-42}$ injection compared to $A \beta_{1-42}$ alone $(\mathrm{p}<0.05)$ (Fig. 7D). Furthermore, the western blot results revealed a significant decrease in the level of PSD95 in the $A \beta_{1-42}$-treated group while treatment with OMNP reduced the effect of $A \beta_{1 \text { - }}$ 42 and significantly increased $(\mathrm{p}<0.01)$ the level of PSD95 compared to $A \beta_{1-42}$ treatment alone mice (Fig. 7D). The brain tissue was also histologically examined for PSD95 expression via immunofluorescence. Representative images (Fig. 7E) showed that $A \beta_{1-42}$ injection reduced the immunofluorescence reactivity for PSD95 (FITC-labeled, green) in the CA2 and DG regions of the hippocampus compared to the control treatment. However, OMNP treatment significantly increased $(\mathrm{p}<0.01)$ the immunofluorescence reactivity for PSD95 compared to treatment with native osmotin $(\mathrm{p}<0.05)$ (Fig. 7E).

\section{The OMNP attenuated A $\beta$ accumulation and $\beta$-site APP-cleaving enzyme-1 (BACE-1)

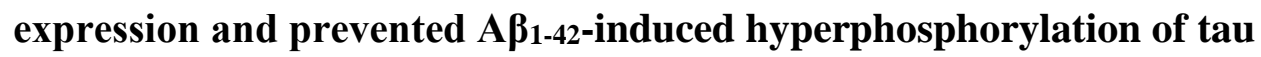

To determine whether $A \beta_{1-42}$ injection promoted $A \beta$ accumulation, we performed a western blot analysis. The results showed that the levels of $A \beta$ were significantly higher in the $A \beta_{1-42}$-treated mice than in the control mice. The OMNP administration ameliorated this effect of $A \beta_{1-42}$, as a significant reduction $(\mathrm{p}<0.01)$ was observed in $\mathrm{A} \beta$ accumulation compared to treatment with bulk osmotin $(\mathrm{p}<0.05)$ (Fig. 8A). To examine plaque formation after $\mathrm{A} \beta_{1-42}$ injection, we performed thioflavin $S$ staining. In the $A \beta_{1-42}$-treated mice, the number of plaques and the plaque burden (\%) were determined, and no plaque formation was observed in the control mice. Treatment with OMNP significantly decreased $(\mathrm{p}<0.01)$ the number of plaques and the plaque burden (\%) (Fig. 8B). 
We also analyzed the immunofluorescence of $A \beta$ in the experimental mice. The OMNP treatment significantly reduced $(\mathrm{p}<0.01)$ the immunofluorescence reactivity of $\mathrm{A} \beta$ (TRITC-labeled, red) in the CA1 and DG regions of the hippocampus in the $A \beta_{1-42}$-treated group showing enhanced neuroprotection (Fig. 8C). Furthermore, we examined the expression of BACE-1 after A $\beta_{1-42}$ injection, and the western blot analysis results showed that $A \beta_{1-42}$ treatment significantly increased BACE-1 expression compared to the control treatment. The expression of active BACE-1 was significantly decreased $(\mathrm{p}<0.05)$ due to treatment free osmotin; however, it was decreased more potently $(\mathrm{p}<0.01)$ by the OMNP treatment (Fig. 8A). We also investigated the phosphorylation of the tau protein (p-tau) in the control and $\mathrm{A} \beta_{1-42}$-treated mice via western blot analysis. Treatment with $A \beta_{1-42}$ increased the level of $p$-tau compared to the control treatment. The $A \beta_{1-42 \text {-induced }}$ hyperphosphorylation of tau was significantly attenuated by OMNP treatment $(\mathrm{p}<0.01)$ compared to treatment with osmotin alone ( $<$ <0.05) (Fig. 8A). 
Figure 8 A
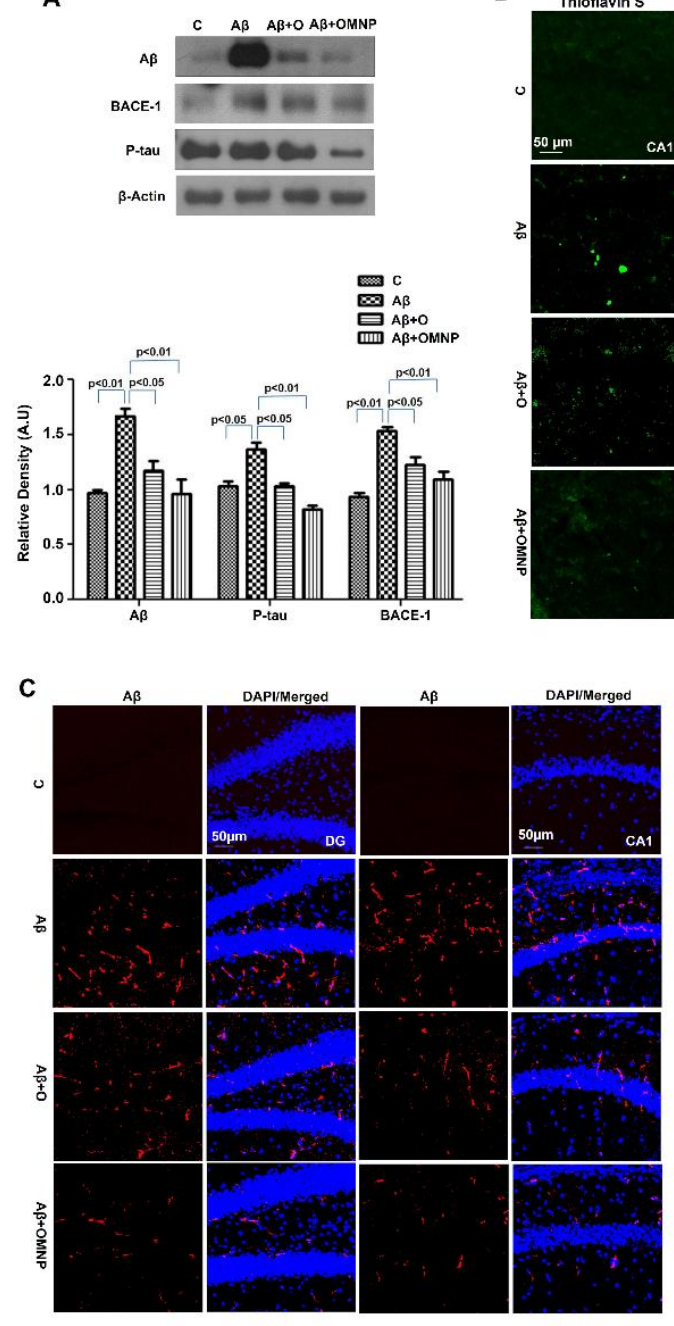

B
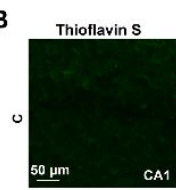

PI/Thioflavin S

PIThioflavin S

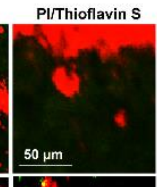

\begin{tabular}{|l|l}
\hline Thioflavin S PIThioflavin S \\
\hline
\end{tabular}

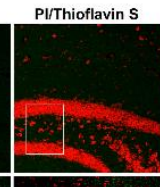

$100 \mu \mathrm{m}$
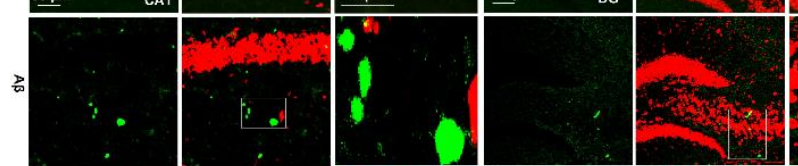

PI/Thioflavin S
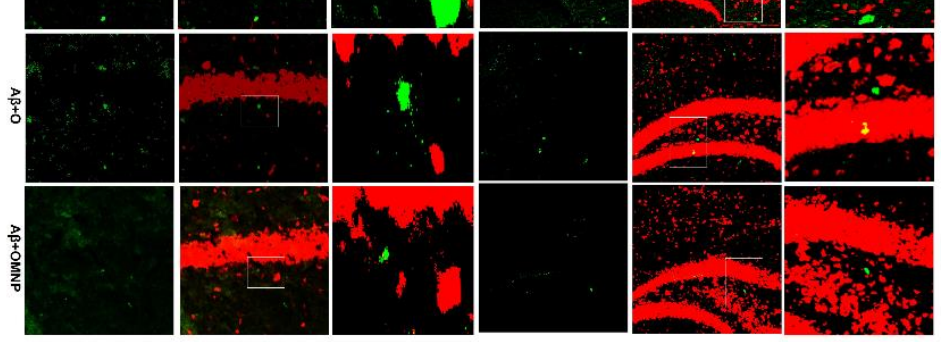

Thioflavin $S \quad \square{ }_{A B}^{c}$
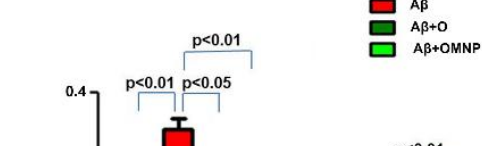

AB+OMNP

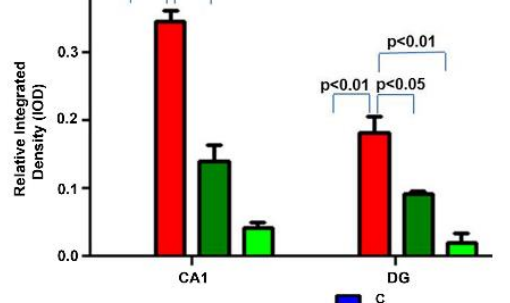

$\square \stackrel{C}{A B}$

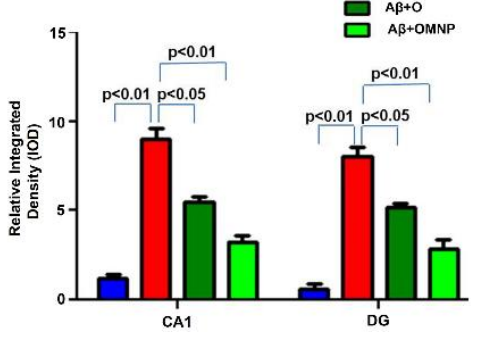

\section{Discussion}

Based on the pioneering idea proposed by Freeman et $\mathrm{al}^{48}$ that fine iron particles could be transported through the vascular system, the use of magnetic particles for the delivery of drugs or antibodies to organs or tissues altered by disease has become an active and attractive field of research. ${ }^{49}$ The proposed method of magnetically guided drug delivery involves the following: 
first, the immobilization of a drug into MNPs; second, the injection of the drug/carrier complex into the subject, either via intravenous (i.v.) or intra-arterial (i.a.) injection; and, finally, the use of high-gradient external magnetic fields to pass the particles through BBB. To increase the biocompatibility of these nanostructures with cells and tissues, they are generally coated with hydrophilic polymers, such as starch or dextran, due to their low toxicity and high affinity for iron oxide (chelation and hydrogen bonding $)^{50}$, whereas the therapeutic agent of interest is either covalently conjugated or ionically bound to the outer layer of the polymer. ${ }^{51}$

In the first phase of this study, we demonstrated the increased sensitivity of FMNPs to an FMF and explored the possibility of using such fluorescent magnetic particles to access the brains of normal mice. An FMF may offer distinct advantages in terms of its ability to minimize cell surface aggregate formation and to maximize the force driving the cellular uptake and transport of particles. We focused on delivery across the intact $\mathrm{BBB}$ in normal mice. Recent studies have also demonstrated the use of an external magnetic field to facilitate the delivery of MNPs across the BBB.$^{52,53}$ Our research demonstrates BBB translocation of FMNPs based on a higher resolution confocal analysis to pinpoint the extravasation of these particles in the brain. Furthermore, unlike in vitro BBB cell culture models with various limitations, our in vivo model is more suitable for studying the complex multi-cellular nature of the $\mathrm{BBB}$ and the pharmaco-distribution of the FMNPs. Moreover, our data indicate that magnet-mediated delivery of FMNPs can occur in the normal brain without disturbing the BBB integrity and that such delivery is not cytotoxic.

The mean diameter of the FMNPs was $350 \mathrm{~nm}$. An examination of the TEM micrographs revealed spherically shaped NPs (Fig. 2A-B). Cell viability studies showed that these magnetic particles were not cytotoxic at all of the tested concentrations (Fig. 2E). Under all of the FMF conditions tested, the transport of FMNPs across the BBB was increased (Fig. 4a-f). In contrast, when the 
magnetic field was held constant, a marked decreased fraction of particles crossed the brain or were actively transported across the BBB ${ }^{30}$ When the FMF was applied, the sticking phenomenon among the particles inside the blood vessels decreased, which enhanced the uptake and transport of magnetic particles across the BBB. ${ }^{28,30}$

Probing the role of endocytosis on the transport of MNPs is very difficult in vivo, and only a few such studies on the middle ear epithelium have been conducted. ${ }^{54,55}$ The Kong et al. reported a possible mechanism regarding how magnetic nanoparticles cross the BBB in vivo in mice due to the application of an external magnetic field. They showed that the $\underline{100 \mathrm{~nm}}$ magnetic nanoparticles, the size of which is close to our OMNPs, can internalize into brain endothelial cells by a process of endocytosis and maintain the barrier properties of the BBB..$^{56}$ Therefore, we assumed that, in our in vivo study, the magnetic nanoparticles were also internalized by the endothelial cells of the BBB by endocytosis mechanisms, and our Evan's blue results are consistent with the previous report that, after MNP injection and exposure to the FMF, the MNPs successfully crossed the BBB without disturbing its integrity.

Submaximal magnetic field strengths have been previously used in vivo to avoid severe particle aggregations that often occur during magnetic drug delivery's experiments. ${ }^{57}$ For the various FMF scenarios, we observed the best results under the condition of a 10-minute exposure time with a 6ampere current at a $0.5-\mathrm{Hz}$ frequency, which induced enhanced uptake and crossing of the intact BBB and increased FMNPs that reached the hippocampus. Increased magnetic forces (or amperes) and increased exposure times led to more FMNPs crossing the BBB. Furthermore, we observed the best result when the frequency of the FMF was $0.5 \mathrm{~Hz}$. Regarding the FMF, as the frequency was increased, less particles stuck to blood vessels, as the positive magnetic force decreased but the negative magnetic force was long enough to release the particles to prevent sticking. However, 
when the frequency was too high $(>0.5 \mathrm{~Hz})$, the negative magnetic force was too small, and the particles did not have enough time to release from the blood walls. In (T. D. DO et al., 2016) ${ }^{58}$ experimental results of FMFs in normal mice illustrate that a 3A current provides higher BBB crossing of MNPs than a $1 \mathrm{~A}$ current. Moreover, frequencies of 0.5 and $1 \mathrm{~Hz}$ have higher BBB crossing in comparison to a frequency of $0.25 \mathrm{~Hz}$. Similarly, extensive simulation studies ${ }^{58}$ with a realistic 3D vessel showed that a frequency of $0.5 \mathrm{~Hz}$ has the best conditions matching to the experimental results. Therefore, in this study, three conditions of 3A- $0.5 \mathrm{~Hz}, 6 \mathrm{~A}-0.5 \mathrm{~Hz}$, and $6 \mathrm{~A}-1$ $\mathrm{Hz}$ were studied and the best condition is chosen as $6 \mathrm{~A}$ and $0.5 \mathrm{~Hz}$ among them. The results from these in vivo experiments suggest that the best FMF can effectively enhance MNP guidance by preventing sticking and aggregation in blood vessels and allowing MNPs to reach the hippocampus within a few minutes of injection without disrupting the BBB (Fig. 5B).

Unlike other drug delivery methods, such as that mediated by antibodies to specific cell surface receptors, the magnetically mediated translocation of MNPs does not appear to induce deleterious signal transduction events and results in minimal accumulation in other organs ${ }^{59}$ After extensively studying the differential effects of FMFs on the uptake and transport of FMNPs into the brains of normal mice, we concluded that all of the applied FMF conditions were effective and that the FMNPs successfully crossed the BBB, reaching the brain within a few minutes of treatment without disrupting the BBB. To understand the potential for toxic effects in vivo in normal mice, we studied the apoptotic markers caspase-3 and PARP-1. We did not observe activation or elevation of the expressions of apoptotic markers caspase-3 and PARP-1 in the brain lysate of normal mice, which was confirmed via western blot, indicating that FMNP injection and exposure to an FMF are not toxic in vivo (Fig. 6A). Several reports have found that iron accumulates in tissues with unremarkable histological changes in vital organs, concluding the safety of the 
respective formulations. ${ }^{60-63} \mathrm{Niss} / \mathrm{cresyl}$ violet staining showed that there was no neurodegeneration after FMNP injection or exposure to an FMF (Fig. 6B). Evans blue dye (EBD) ${ }^{64}$ is a commonly used tracer for the estimation of plasma volume in humans and the study of vascular permeability in animal models. Our results demonstrated that FMNP administration and exposure to an FMF did not change the BBB integrity in normal mice and did not induce a major disruption of the endothelial barrier because there was no leakage of Evans blue observed in the brains of mice. Since the blood-brain barrier was leakier in a group of people with Alzheimer's disease than their healthy counterparts, ${ }^{65,66}$ OMNPs can reach to the brain of AD mice without further breaking anymore the BBB integrity.

The present study is the first report to provide evidence that osmotin-conjugated magnetic

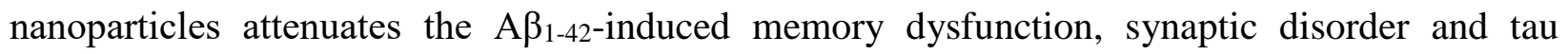
hyperphosphorylation in mice hippocampus and to report the best condition of FMFs for the drug delivery. The osmotin covalently binds to nanoparticles through the interaction between amine group on osmotin and carboxyl group on magnetic particles. Molecules that contain amine groups such as protein (osmotin) or peptide, can be conjugated to the surface functional group -COOH of magnetic beads easily. The MNPs with dextran coating stabilize the nanoparticles, achieve excellent dispersion and stabilizes the colloidal solution. ${ }^{67,68}$ Furthermore, we did not observe any type of precipitation of OMNP which is the most significant feature when the protein-conjugated particles are going bad. C. Wang et al, 2013 reported that the release of doxorubicin (DOX) from magnetic nanoparticles is $\mathrm{pH}$ dependent. ${ }^{69}$ They investigated the drug-releasing behaviors of Fe3O4@PPy-PEG-DOX under different pH values like in $\mathrm{pH}$ 5.0, 6.0, and 7.4 phosphate buffers. Within $24 \mathrm{~h}$, about $48 \%$ of DOX was released from the nanocomposite at $\mathrm{pH} 5.0$, compared with $13 \%$ and $4 \%$ of DOX release at $\mathrm{pH} 6.0$ and 7.4, respectively. ${ }^{69}$ The covalent bonds in the 
nanoparticles-drug conjugates can hold the drug firmly in the circulation at physiological $\mathrm{pH}$ conditions, and there will be less drug released into healthy tissue and can only be released when there is an acidic environment. ${ }^{70}$ Moreover, another study also revealed that the $\mathrm{pH}$ in the brains of AD patients is lower than that in the brains of healthy individuals. ${ }^{71}$ So, on the basis of previous research work, the one possible mechanism/explanation for osmotin release is that the therapeutic agent (osmotin) will show controlled release at the target site (AD brain) in acidic $\mathrm{pH}$ condition and will not be released at physiological $\mathrm{pH}^{70}$ of the body.

The $\mathrm{A} \beta_{1-42}(3 \mu \mathrm{L} / 5 \mathrm{~min} / \mathrm{mouse})$ triggered memory dysfunction, an important indicator of synaptic disorder (a key feature of early phase AD), and hyperphosphorylated tau. The intracerebroventricular $A \beta$ injection model is a useful complement to transgenic mouse models ${ }^{72}$ for the development and evaluation of therapeutic approaches to AD pathology because the mechanisms underlying many characteristics of $\mathrm{AD}$, including the induction of tau phosphorylation, synaptotoxicity, apoptosis and neurodegeneration, remain elusive.

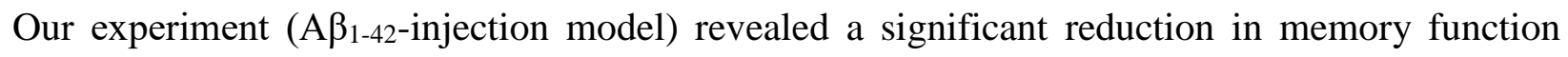
observed through the MWM and Y-Maze test. We observed that, compared to treatment with osmotin alone, OMNP treatment improved memory, assessed by a reduction in the escape latency and the number of platform crossings during the probe test. In the Y-maze, we observed reduced spontaneous alteration behavior related to the hippocampus. ${ }^{73}$ We observed that the OMNP treatment ameliorated the effects of $A \beta_{1-42}$ on the spontaneous alteration behavior, thus reducing the degree of spatial memory impairment. The observed improvements in memory function for the OMNP treatment, demonstrating the neuroprotective effect of OMNP against $A \beta_{1-42 \text {-induced }}$ memory impairment. 
Landmarks studies have reported $\mathrm{A} \beta$-induced synaptic loss and disorders in animal models of AD. ${ }^{74}$ The expression of the presynaptic marker, synaptophysin, was decreased in the brains of patients with $\mathrm{AD}$ and in an $\mathrm{A} \beta$ animal model of $A D .^{75,76}$ Our results showed that $\mathrm{A} \beta_{1-42 \text {-treated }}$ mice significantly reduced synaptophysin levels in the hippocampus. Moreover, a decreased level of the postsynaptic protein marker, PSD95, is also implicated in the A $\beta$ model of AD. ${ }^{74}$ The

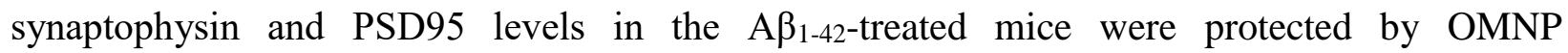
administration, thereby suggesting that protecting pre-and post-synaptic protein markers improves spatial memory.

In $\mathrm{AD}, \mathrm{A} \beta$ production and aggregation in the human brain has been associated with neuronal dysfunction and memory disorders ${ }^{77}$ BACE-1 is the primary initiating enzyme, and its activity is the rate-limiting step involved in APP processing and A $\beta$ production. ${ }^{78}$ The elevated expression of activated BACE-1 has been examined in the brain during late-onset sporadic AD, which is associated with neuronal loss and spatial memory impairment in 5XFAD APP/PS1 mice. ${ }^{79,80}$ Interestingly, recent studies have shown that BACE-1 expression is up-regulated by $\mathrm{A} \beta 1-42 .{ }^{81}$ The results of the present study consistently showed increased levels of BACE-1 expression in the A $\beta_{1}$ 42-treated mice. The total $A \beta$ level and $A \beta_{1-42}$-induced BACE-1 expression after $A \beta_{1-42}$ injection were attenuated by OMNP treatment (Fig. 8A-C). Recently, studies have reported that soluble A $\beta$ oligomers, generated from synthetic $\mathrm{A} \beta$ peptides and extracted from the brain of patients with $\mathrm{AD}$, promote hyperphosphorylation of the tau protein. ${ }^{82}$ Hyperphosphorylated tau induced memory impairment and loss of functional synapses in a transgenic mouse model. ${ }^{83}$ Our results showed that OMNP alleviates the hyperphosphorylation of the tau protein (Fig. 8A).

\section{Conclusion}


This study for the first time showed its effectiveness for treating of Alzheimer's disease using OMNP and an electromagnetic drug delivery method for guiding FMNPs to the deep brain region of mice. Our study demonstrates the ability to regulate the CNS distribution of FMNPs using an external electromagnetic field (i.e., functionalized magnetic field), and demonstrate the ability of FMNPs to cross the BBB and to accumulate in the hippocampus of mice brains, which can be beneficial for treatments of various CNS diseases. Our results also demonstrate that the OMNP

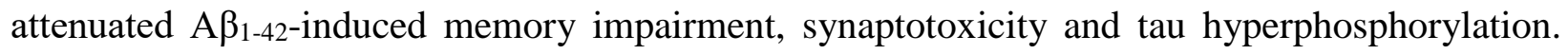
Based on these results, the combination of osmotin and a magnetic nanoparticles-based delivery system with external functional magnetic guidance may open new avenues for therapeutic approaches for the treatment of various chronic and metabolic diseases, including neurodegenerative diseases, such as AD.

\section{Experimental Section}

Most parts of this section are provided in the Supplementary Information. ${ }^{84-87}$

\section{Properties of Fluorescent Carboxyl Magnetic Nile Red Particles (FMNPs),}

The fluorescent carboxyl magnetic Nile Red particles (FMNPs), 1\% w/v, polymerized with styrene, were purchased from Spherotech (Catalog No: FCM-02556-2). The nanoparticle size was 0.20$0.39 \mu \mathrm{m}$ in diameter and its average size was $0.35 \mu \mathrm{m}$. Based on conductometric titration, the parking area was 75 Angstroms squared with $5.13 \times 10^{\wedge} 5$ carboxyl groups/bead. The FMNPs excitation and emission spectra ranged from $450-550 \mathrm{~nm}$ and 500-600 nm respectively, and it showed highly efficient fluorescence in the Fluorescein isothiocyanate channel. The FMNPs 
Images were captured with a confocal laser scanning microscope (FluoView FV 1000;Olympus, Tokyo, Japan), with argon ion laser.

\section{Preparation of Osmotin-Loaded Magnetic Nanoparticles (OMNP)}

The dextran-coated Fe3O4 magnetic nanoparticles (MNPs) were purchased from MagQu Co., Ltd. Taiwan. Osmotin was conjugated with dextran-coated magnetic nanoparticles using a NanoQCarboxyl Labeling Kit (Cat. No. KT-COO-0060-ISE).

\section{Electromagnetic drug delivery actuator and functionalized magnetic field generation}

The proposed electromagnetic actuator consisted of a two-coil core system. The coils were made of 1-mm diameter copper wire with 7000 turns and diameter $\mathrm{d}=1.0 \mathrm{~mm}$. For each coil, a core was added to increase the magnetic field density. The coils were made of a soft magnet cobalt-iron alloy, type VACOFLUX 50. The coils and cores were used to produce a magnetic field and to concentrate the field in the working area, respectively. The proposed actuation system can generate adequate magnetophoretic forces for nanoparticle steering in a vascular model. ${ }^{29}$ Figure 3 shows a picture and the geometric specifications of the proposed electromagnetic actuator. Figure 3A illustrates the experimental setup of the electromagnetic actuator system. The magnetic field at the ROI had a $60-\mathrm{mm}$ diameter at the center of the actuation system and was designed for tests on mice. The magnetic force was controlled using DC power supplies and regulating the current in the coil. Currents up to 17 A could be applied to the coil-core system, which corresponded to a resistance of $20 \Omega$ and an inductance of $0.42 \mathrm{H}$. The rated power of the DC power supply was 6 $\mathrm{kW}$.

The functionalized magnetic field was introduced to avoid the sticking phenomenon and to increase the rate of MNP uptake. ${ }^{28,29}$ In this scheme, we sequentially turned on and off each coil 
to produce a positive- and negative-pulsed magnetic field. In the proposed approach, the functionalized magnetic field scheme is the combination of two pulsed magnetic fields in reverse directions. Through our simulations, FMF is proven to be effective and prevent sticking and aggregation. Figure. 3B shows the current flow in the coils, the magnetic force generated in each coil, and the total functionalized magnetic force. The on duration of the left coil compared to the right coil was set to $3: 1$, which were chosen based on our extensive simulation studies and in vitro experimental studies with a Y-channel. ${ }^{28,29}$

The control system of the electromagnetic actuation is illustrated in Figure 3C. The control system activates the actuators based on the designed FMF to promote BBB crossing. The gradient of the magnetic field (left coil 6 Ampere) has been simulated in Figure 3D. It has high intensity in the region of interest (the mouse brain). The proposed FMF excites particle movement in the vascular system and allows the particles to reach broader tissue sites in the mouse brain by overcoming sticking and aggregation.

\section{Fluorescent magnetic particle (FMNPs) treatment in normal mice}

The mice were randomly divided into the following seven groups. All mice were treated intravenously with $0.4 \mathrm{~mL}$ fluorophore-labeled FMNPs and then exposed to various conditions of FMFs for different time intervals. Using Nile Red fluorescent carboxyl magnetic particles (FMNPs), we demonstrated the ability of FMNPs to access the mouse brain in vivo by crossing the normal intact BBB under six different FMF conditions, and the details are provided in Table 1. 
Table 1. Table shows the details of the in vivo experiment (Figures 4 and 5), including the mouse groups, the FMF conditions, the exposure time to the FMF after i.v. injection of the FMNPs, the dose of the FMNPs and the size of the FMNPs.

\begin{tabular}{|c|c|c|c|c|}
\hline $\begin{array}{c}\text { Mice } \\
\text { groups }\end{array}$ & FMF & $\begin{array}{c}\text { Exposure time } \\
\text { to FMF }\end{array}$ & FMNPs (dose) & $\begin{array}{l}\text { FMNPs } \\
\text { (size) }\end{array}$ \\
\hline a) & $\begin{array}{c}3 \mathrm{~A} \\
(0.5 \mathrm{~Hz})\end{array}$ & 5 minutes & $400 \mu \mathrm{L}$ & $200-390 \mathrm{~nm}$ \\
\hline b) & $\begin{array}{c}3 \mathrm{~A} \\
0.5 \mathrm{~Hz})\end{array}$ & 10 minutes & $400 \mu \mathrm{L}$ & $200-390 \mathrm{~nm}$ \\
\hline c) & $\begin{array}{c}6 \mathrm{~A} \\
(0.5 \mathrm{~Hz})\end{array}$ & 5 minutes & $400 \mu \mathrm{L}$ & $200-390 \mathrm{~nm}$ \\
\hline d) & $\begin{array}{c}6 \mathrm{~A} \\
(0.5 \mathrm{~Hz})\end{array}$ & 10 minutes & $400 \mu \mathrm{L}$ & $200-390 \mathrm{~nm}$ \\
\hline e) & $\begin{array}{c}6 \mathrm{~A} \\
(1.0 \mathrm{~Hz})\end{array}$ & 5 minutes & $400 \mu \mathrm{L}$ & $200-390 \mathrm{~nm}$ \\
\hline f) & $\begin{array}{c}6 \mathrm{~A} \\
(1.0 \mathrm{~Hz})\end{array}$ & 10 minutes & $400 \mu \mathrm{L}$ & $200-390 \mathrm{~nm}$ \\
\hline g) & NIL & NIL & $400 \mu \mathrm{L}$ & $200-390 \mathrm{~nm}$ \\
\hline
\end{tabular}

Mice were sacrificed after treatment. All efforts were made to minimize the number of mice used and their suffering. The experimental procedures were approved by the animal ethics committee of the Division of Applied Life Sciences, Department of Biology at Gyeongsang 
National University, South Korea.

\section{Drug treatment}

Human $A \beta_{1-42}$ peptide was prepared as a stock solution at a concentration of $1 \mathrm{mg} / \mathrm{ml}$ in sterile saline solution, followed by aggregation via incubation at $37^{\circ} \mathrm{C}$ for 4 days. The aggregated $\mathrm{A} \beta_{1-42}$ peptide or vehicle $(0.9 \% \mathrm{NaCl}, 3 \mu \mathrm{L} / 5 \mathrm{~min} /$ mouse $)$ was stereotaxically administered intracerebroventricularly using a Hamilton microsyringe (- $0.2 \mathrm{~mm}$ anteroposterior (AP), $1 \mathrm{~mm}$ mediolateral (ML) and $-2.4 \mathrm{~mm}$ dorsoventral (DV) to the bregma) under anesthesia in combination with $0.05 \mathrm{ml} / 100 \mathrm{~g}$ body weight Rompun (xylazine) and $0.1 \mathrm{ml} / 100 \mathrm{~g}$ body weight Zoletil (ketamine). We performed the stereotaxic surgical procedure in a separate heated room in which the heating system was designed to control the body temperature (maintained at $36{ }^{\circ} \mathrm{C}-$ $37^{\circ} \mathrm{C}$ ). The osmotin-treated group received a single dose of $15 \mu \mathrm{g} / \mathrm{g}$ osmotin (dissolved in $0.9 \%$ $\mathrm{NaCl}$ saline) administered intravenously (i.v.). The OMNP-treated group received a single dose of $15 \mu \mathrm{g} / \mathrm{g}$ of OMNP (dissolved in $0.9 \% \mathrm{NaCl}$ saline) administered intravenously (i.v.). The control mice received an equal volume of $0.9 \% \mathrm{NaCl}$ saline i.v. at 40 days post-injection with $0.9 \% \mathrm{NaCl}$.

\section{Data analysis}

The western blot bands were scanned and analyzed via densitometry using a Sigma Gel System (SPSS Inc., Chicago, IL). The density values were expressed as the means \pm standard error mean (SEM). Image-J software was used for the immunohistological quantitative analysis. A one-way analysis of variance (ANOVA) followed by a two-tailed independent Student's t-test was used to compare the treated groups and the control. The calculations and graphs were made using Prism 5 software (Graph-Pad Software, In., San Diego, CA). For the FMNP treatment in normal mice, a p-value $<0.01$ was considered statistically significant. The symbol $* * *$ represents a significant difference compared to the control group $(* * * \mathrm{p}<0.0001)$. The symbol ** represents a significant 
difference within the experimental groups that received the functionalized magnetic field

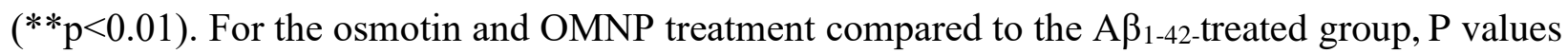
less than 0.05 were considered statistically significant.

\section{Acknowledgement}

This research was supported by the Brain Research Program through the National Research

Foundation of Korea funded by the Ministry of Science, ICT \& Future Planning (2016 M3C7A1904391 \& 2012-0009524).

\section{References}

1 W. Xia, Curr Opin Investig Drugs. 2003, 2, 55-59.

2 S. A. Frautschy, G. M. Cole, Mol Neurobiol. 2010, 41, 392-409.

3 R. Sultana, M. Perluigi, D. A. Butterfield, Acta Neuropathol. 2009, 118, 131-150.

4 D. J. Selkoe, Neuron 1991, 6, 4487-4498.

5 K. H. Chan, k. S. L. Lam, O. Y. Cheng, et al., Plos One. 2012, 7, e52354.

6 M. P. Lamert, A. K. Barlow, B. A. Chromy, et al., Proc. Natl. Acad Sci USA. 1998, 95, 6448-6453.

7 J. H. Jhoo, H. C. Kim, T. Nabeshima, et al., Beh Bra Res. 2004, 155, 185-196.

8 B. J. C. Cornelissen, V. Hooft, R. A. Huijsduijnen, J. F. A. Bol, Nature 1986, 321, 531-532.

9 L. R. Abad, M. P. D’Urzo, D. Liu, M. L. Narasimhan, M. Reuveni, J. K. Zhu, et al. Plant Sci 1996, 118, 11-23.

10 S. A. Shah, H. Y. Lee, R. A. Bressan, D. J. Yun, M. O. Kim, Cell Death Dis. 2014, 5, 1026.

11 M. I. Naseer, et al., Cell Death Dis. 2014, 5, 1150. 
12 T. Ali, G. H. Yoon, S. A. Shah, H. Y. Lee, M. O. Kim, Sci Rep. 2015, 5, 11708.

13 S. A. Shah, G. H. Yoon, S. S. Chung, M. N. Abid, T. H. Kim, H. Y. Lee, M. O. Kim, Molecular Psychiatry. 2016, 1-10.

14 E. Karran, M. D. Mercken, B. Strooper, Nat Rev Drug Discov 2011, 10, 698-712.

15 U. Schwertmann, R. M. Cornell, VCH,Weinheim, Cambridge. 1991

16 D. D. Star, R. Weissleder, G. Elizondo, P. F. Hahn, S. Saini, L. E. Todd, J. Wittenberg, J. T. Ferrucci, Radiology. 1988, 168, 297-301.

17 S. Saini, J. T. Ferrucci, Radiology 1988, 169, 656.

18 P. F. Hahn, D. D. Stark, R. Weissleder, G. Elizondo, S. Saini, J. T. Ferrucci, Radiology. 1990, 174, 361-366.

19 C. W. Hung, T. R .P. Holomana, P. Kofinas, W. E. Bentley, Biochem. Eng. J. 2008, 38, 164 170 .

20 C. C. Berry, A. S. G. Curtis, J Phys D: Appl Phys. 2003, 36, 198-206.

21 C. C. Berry, S. Wells, S. Charles, A. S .G. Curtis, Biomaterials, 2003, 24, 4551-7.

22 S. Laurent, D. Forge, M. Port, A. Roch, C. Robic, E. L. Vander, R. N. Muller, Chem Rev. 2008, 108, 2064-2110.

23 S. M. Janib, A. S. Moss, J. A. MacKay, Adv. Drug Delivery Rev. 2010, 62, 1052-1063.

24 J. Bar, R. S. Herbst, A. Onn, Expert Opin. Drug Deliv. 2009, 6, 1003-1016.

25 V. P. Torchilin, Handb. Exp. Pharmacol. 2010, 197, 3-53.

26 K. Mosbach, U. Schroder, FEBS Lett. 1979, 102, 112-116.

27 J. Johnson, T. Kent, J. Koda, C. Peterson, S. Rudge, G. Tapolsky, Eur. Cells Mater. 2002, $3,12-15$.

28 M. D. Tehrani, J. H. Yoon, M. O. Kim, J. Yoon, IEEE Trans. Biomed. Eng. 2015, 62, 303313.

29 M. D. Tehrani, M. O. Kim J. Yoon, IEEE Trans. Magn. 2014, 50, 5100412.

30 T. D. Do, F. U. Amin, Y. Noh, M. O. Kim, J. Yoon, J. Biomed. Nanotechnol. 2016, 12, 569574.

31 L. R. Squire, Psychol Rev 1992, 99, 195-231. 
32 K. A. Min, M. C. Shin, F. Yu, M. Yang, A. E. David, V. C. Yang, G. R. Rosania, ACS Nano. 2013, 7, 2161-2171.

33 T. J. Brunner, P. Wick, P. Manser, P. Spohn, R. N. Grass, L. K. Limbach, A. Bruinink, W. J. Stark, Environ. Sci. Technol. 2006, 40, 4374-4381.

34 A. Nel, T. Xia, L. Mädler, N. Li, Science, 2006, 311, 622-627.

35 G. Oberdorster, E. Oberdorster, J. Oberdorster, Environ Health Perspect. 2005, 113, 823839.

36 M. C. Powell, M. S. Kanarek, WMJ, 2006, 105, 18-23.

37 M. C. Powell, M. S. Kanarek, WMJ, 2006, 105, 16-20.

38 M. N. Moore, Environ. Int. 2006, 32, 967-976.

39 M. Johannsen, U. Gneveckow, K. Taymoorian, B. Thiesen, N. Waldöfner, R. Scholz, K. Jung, A. Jordan, P. Wust, S.A. Loening, Int. J. Hyperthermia, 2007, 23, 315-323.

40 G. J. Harry, E. Tiffany-Castiglioni, Expert Opin. Drug Metab. Toxicol. 2005, 1, 701-713.

41 S. T. Stern, S. E. McNeil, Toxicol. Sci. 2008, 101, 4-21.

42 M. I. Gregersen, R. A. Rawson, Am J Physiol 1943, 138, 698-707.

43 T. M. Sutherland, D. A. Young, J Physiol, 1966, 183, 112-122.

44 O. Steinwall, I. Klatzo, J Neuropathol Exp Neurol, 1966, 25, 542-559.

45 A. Saria, J. M. Lundberg, J Neurosci Methods, 1983, 8, 41-49.

46 R. A. Clasen, S. Pandolfi, G. M. Hass, J Neuropathol Exp Neurol. 1970, 29, 266-284.

47 K. B. Chen, E. Y. Kuo, K. S. Poon, K. S. Cheng, C. S. Chang, Y. C. Liu, T. W. Lai, Neuroreport. 2012, 23, 699-701.

48 M. W. Freeman, A. Arrot, H. H. L. Watson, J. Appl. Phys. 1960, 31, 404.

49 S. Goodwin, C. Peterson, C. Hoh, C. Bittner, J. Magn. Magn. Mater. 1999, 194, 132-139.

50 O. Veiseh, J. W. Gunn, M. Zhang, Adv Drug Deliv Rev 2010, 62, 284-304.

51 T. K. Jain, M. A. Morales, S. K. Sahoo, et al., Mol Pharm. 2005, 2, 194-205.

52 Z. M. Saiyed, N. H. Gandhi, M. P. Nair, Int. J. Nanomedicine. 2010, 5, 157-166.

53 L. Han, A. Zhang, H. Wang, P. Pu, C. Kang, J. Chang, J. Appl. Polym. Sci. 2011, 121, 34463454. 
54 F. G. Mondalek, Y. Y. Zhang, B. Kropp, R. D. Kopke, X. Ge, R. L. Jackson, K. J. Dormer, J. Nanobiotechnol. 2006, 4, 1-9.

55 K. Dormer, C. Seeney, K. Lewelling, G. Lian, D. Gibson, M. Johnson, Biomaterials 2005, 26, 2061- 2072.

56 S. D. Kong, J. Lee, S. Ramachandran, B. P. Eliceiri, V. Shubayev, R. Lal, S. Jin, J Control Release 2012, 164, 49-57.

57 X. Gao, Y. Wang, K. Chen, B. P. Grady, K. J. Dormer, R. D. Kopke, J. Nanotechnol. Eng. Med. 2010, 1, 1-6.

58 T. D. Do, F. U. Amin, Y. Noh, M. O. Kim, J. Yoon. IEEE Trans. Magn. 2016, 52, 9100304.

59 G. Tosi, A.V. Vergoni, B. Ruozi, L. Bondioli, L. Badiali, F. Rivasi, L. Costantino, F. Forni, M. A. Vandelli, J. Control. Release 2010, 145, 49-57.

60 L. L. Muldoon, M. Sàndor, K. E. Pinkston, E. A. Neuwelt, Neurosurgery, 2005, 57, 785796.

61 M. D. Dunning, A. Lakatos, L. Loizou, M. Kettunen, C. ffrench-Constant, K. M. Brindle, R. J. Franklin, J. Neurosci. 2004, 24, 9799-9810.

62 J. S. Kim, T. J. Yoon, K. N. Yu, B. G. Kim, S. J. Park, H. W. Kim, K. H. Lee, S. B. Park, J. K. Lee, M. H. Cho, Toxicol. Sci. 2006, 89, 338-347.

63 H. L. Ma, X. R. Qi, W. X. Ding, Y. Maitani, T. Nagai, J. Biomed. Mater. Res. A. 2008, 84, 598-606.

64 H. M. Evans, W. Schulemann, Science 1914, 39, 443-454.

65 H. J. Haar, S. Burgmans, J. F. Jansen, M. J. Osch, M. A. Buchem, M. Muller, P. A. Hofman, F. R. Verhey, W. H. Backes. Radiology. 2016, 281, 527-535.

66 A. Montagne, S. R. Barnes, M. D. Sweeney, et al. Neuron. 2015, 85, 296-302.

67 C. C. Berry, A. S. G. Curtis. J Phys D: Appl Phys 2003a, 36, 198-206.

68 C. C. Berry, S. Wells, S. Charles, A. S. G. Curtis. Biomaterials 2003b, 24, 4551-7.

69 C. Wang, H. Xu, C. Liang, Y. Liu, Z. Li, G. Yang, L. Cheng, Y. Li, Z. Liu, ACS Nano 2013, 7, 6782-6795.

70 J. Kopeček, Adv. Drug Deliv. Rev. 2013, 65, 49-59.

71 E. S. Song, M. A. Juliano, L. Juliano, L. B. Hersh, Journal of Biological Chemistry. 2003, 278, 49789-49794.

72 D. S. Woodruff-Pak, J Alzheimers Dis 2008, 15, 507-521. 
73 N. J. Broadbent, R. L. Squire, R. E. Clark, Proc Natl Acad Sci USA 2004, 101, 1451514520.

74 S. Tu, S. Okamoto, S. A. Lipton, et al., Mol Neurodegener. 2014, 9, 48.

75 T. Ahmad, S. A. Enam, A. H. Gillani, Neuroscience 2010, 169, 296-1306.

76 P. M. Canas, L. O. Porciuncula, G. M. A. Cunha, et al., JNeurosci. 2009, 29, 14741-14751.

77 C. Haass, D. J. Selkoe, Nat Rev Mol Cell Biol. 2007, 8, 101-112.

78 B. Liang, B. Y. Duan, X. P. Zhou, et al., J Biol Chem. 2010, 285, 27737-27744.

79 L. B. Yang, K. Lindholm, R. Yan, et al., Nat Med. 2003, 9, 3-4.

80 M. Ohno, S. L. Cole, M. Yasvoina, et al., Neurobiol Dis. 2007, 26, 134-145.

81 M. Guglielmotto, et al., J Alzheimers Dis. 2011, 27, 871-883.

82 T. Ma, N. Tzavaras, P. Tsokas, et al., J Neurosci. 2011, 31, 17537-17546.

83 K. Schindowski, A. Brettevillite, K. Leroy, et al., Am J Pathol. 2006, 169, 599-616.

84 N. K. Singh, C. A. Bracker, P. M. Hasegawa, A. K. Handa, Plant Physiol. 1987, 85, 529536.

85 M. Shah, M. Naseer, M. H. Choi, M. O. Kim, S. C. Yoon, Int. J. Pharm. 2010, 400, 165175.

86 K. Liu, S. Mori, H. K. Takahashi, et al., FASEB J 2007, 21, 3904-3916.

87 A. Bretteville, F. Marcouiller, C. J ulien, et al., S Rep 2012, 2, 480.

\section{Figure legends}

Fig. 1 Schematic representation of the differential effects of the functionalized magnetic field on the transport of magnetic particles across the intact blood brain barrier in normal mice. In our experimental setup, the functionalized magnetic field was generated using an electromagnetic actuator, and the time for each experiment was 10 minutes, which is 9 times shorter than in the previously reported uptake and transport studies. Our results showed that, under all of the observed 
functionalized magnetic field conditions, the magnetic particles successfully crossed the BBB and reached the brain. Importantly, we did not observe any histological changes or neurotoxicity in the brain after the experiments. Moreover, the blood brain barrier integrity was also not disrupted by magnetic particle administration and the functionalized magnetic field.

Fig. 2 Morphological observations and in vitro cytotoxicity of the magnetic particles (A) a TEM micrograph of the FMNPs (scale bar $=200 \mathrm{~nm}$ ); (B) a magnified TEM micrograph of the FMNPs $($ scale bar $=50 \mathrm{~nm}) ;(C)$ a TEM micrograph of the dextran-coated MNPs (scale bar = $200 \mathrm{~nm})$; and (D) a TEM micrograph of the dextran-coated MNPs (scale bar $=100 \mathrm{~nm}$ ). All three nanoparticles cytotoxicity profiles were studied in normal HT-22 cells and normal SH-SY5Y cells using an MTT assay. (E) The MTT assay of the FMNPs in HT-22 cells; (F) The MTT assay of the FMNPs in SH-SY5Y cells; (G) The MTT assay of the Osmotin, MNPs and the OMNP in HT-22 cells; $(\mathrm{H})$ The MTT assay of the Osmotin, MNPs and the OMNP in SH-SY5Y cell lines. Four concentrations, ranging from 50 to $200 \mu \mathrm{g} / \mathrm{mL}$, of each of the test sample, FMNPs, MNPs, OMNP and free osmotin, were used. We observed that the nanoparticles were biocompatible in both types of cells.

Fig. 3 (A) Experimental setup of the electromagnetic drug delivery system for guidance of the nanocontainer-drug conjugates in vivo (B) The input current to each coil to generate the positive and negative pulsed magnetic field (C) A schematic of the proposed drug delivery system consisting of the magnetic field function, the actuation system, and the control system setup (D) The system in practice has been simulated (left coil 6 A) to show the distribution and direction of the magnetic force. 
Fig. 4 A functionalized magnetic force enhances BBB crossing and transport of FMNPs in the brain. The confocal analysis demonstrated accumulation of the FMNPs in the cortex facilitated by the application of an FMF. Representative images of brain sections from the mice.

(a) FMNP + FMF of $3 \mathrm{~A}, 0.5 \mathrm{~Hz}$ for 05 minutes.

(b) FMNP + FMF of $3 \mathrm{~A}, 0.5 \mathrm{~Hz}$ for 10 minutes.

(c) FMNP + FMF of $6 \mathrm{~A}, 0.5 \mathrm{~Hz}$ for 05 minutes.

(d) FMNP + FMF of 6 A, $0.5 \mathrm{~Hz}$ for 10 minutes.

(e) FMNP + FMF of $6 \mathrm{~A}, 1.0 \mathrm{~Hz}$ for 05 minutes.

(f) FMNP + FMF of $6 \mathrm{~A}, 1.0 \mathrm{~Hz}$ for 10 minutes.

(g) Control group, i.v. injection of FMNPs but with no exposure to an FMF.

Scale bar $=50 \mu \mathrm{m}(\mathrm{a}-\mathrm{g})$

Histogram showing the results analyzed using Image J. The data are expressed as the mean \pm SEM of the experiments performed in triplicate $(n=3)$. Significant differences were evaluated using a one-way analysis of variance (ANOVA) followed by a Student's t-test. Differences were considered statistically significant. Symbol $* * *$ represents a significant difference compared to the control group $(* * * \mathrm{p}<0.0001)$. Symbol $* *$ represents a significant difference within the experimental groups supplied with the functionalized magnetic field $(* * p<0.01)$.

Fig. 5 (A) FMNPs reached the hippocampus under a 6-A, 0.5-Hz FMF (Figure 5A, c-d). However, at all the other FMF conditions, we did not observe the presence of FMNPs in the hippocampus (Figure 5A, a, b, e, f). Figure $5 \mathrm{~B}$ shows that the FMNPs are present in the CA1, CA3 and DG regions of the hippocampus after exposure for 10 minutes to the 6-A, 0.5-Hz FMF.

Fig. 6 FMNP administration and exposure to a FMF induced no toxicity in vivo. (A) Representative western blots of caspase-3 and PARP-1 are sown. $\beta$-actin was used as a loading 
control. (B) Nissl staining was performed to observe the extent of neuronal cell death. Representative photomicrographs of cresyl violet-stained brain slices after FMNP administration and exposure to a FMF are shown.

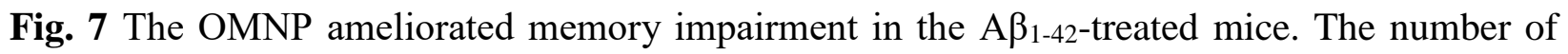
mice $(n=13)$ per group was used for the behavioral analysis. (A) The mean escape latency (sec) to the hidden platform during training session. (B) The number of platform crossings over the previous platform place during the probe test. (C) The percentage of spontaneous alteration behavior. (D) Immunoblot analysis of synaptophysin and PSD95 in the hippocampus of the mice. The bands were quantified using Sigma Gel software, and the differences are represented by a histogram. $\beta$-actin was used as a loading control. The density values are expressed in arbitrary units (A.U) as the means \pm S.E.M. for the respective indicated protein ( $n=8$ mice/group). (E) The immunofluorescence of PSD95 was used as the immunoreactivity of the hippocampus of experimental mice ( $\mathrm{n}=5$ mice/group). Magnification 10x. Scale bar $=50 \mu \mathrm{m}$. P values less than 0.05 were considered statistically significant.

Fig. 8 The OMNP alleviated A $\beta$ accumulation, $\beta$-site APP cleaving enzyme 1 (BACE-1) overexpression and $A \beta$-induced tau hyperphosphorylation. (A) Immunoblot analysis of $A \beta$, BACE-1 and p-tau in the hippocampus of the mice. The bands were quantified using Sigma Gel software, and the differences are represented by a histogram. $\beta$-actin was used as a loading control. The density values are expressed in arbitrary units (A.U) as the means \pm S.E.M. for the respective indicated protein ( $n=8$ mice/group). (B) Thioflavin $S$ staining demonstrating the formation of $A \beta$ plaques at 40 days post- $\mathrm{A} \beta_{1-42}$ injection. Treatment with the OMNP significantly reduced the number and burden of plaques (\%) compared with $A \beta_{1-42}$ treatment alone ( $\mathrm{n}=5$ mice/group). Magnification 10x. Scale bar $=100 \mu \mathrm{m}$. (C) Immunofluorescence of $A \beta$ was used as the 
immunoreactivity of the hippocampus of experimental mice ( $\mathrm{n}=5 \mathrm{mice} / \mathrm{group}$ ). Magnification

10x. Scale bar $=50 \mu \mathrm{m}$. $\mathrm{P}$ values less than 0.05 were considered statistically significant. 